\title{
Analysis of Morphing Airfoil Structures and Fabrication of the Wing using the Concept of Additive Manufacturing
}

\author{
${ }^{1}$ Dr. R Rajendran, ${ }^{2}$ Govind, ${ }^{3}$ Yogeshwara V Bhat, ${ }^{4}$ Vishisht Adithyan, ${ }^{5}$ Ananya C \\ ${ }^{1}$ Senior Professor, Department of Aeronautical Engineering, Dayananda Sagar College of Engineering Bangalore, India. \\ 2,3,4,5 Student, Department of Aeronautical Engineering, Dayananda Sagar College of Engineering Bangalore, India.
}

\begin{abstract}
This paper briefs about the morphing airfoil with variable camber and it makes use of compliant rib mechanism. Lightweight system for actuation, complaint internal structure and a flexible skin are some of the key requirements for such mechanisms. Wing morphing is a biologically inspired technique where-in, the change in shape of wings can offer various advantages compared to the conventional solutions we currently have. In this research, we have used the combination of materials such as PLA and TPU in the wing prototype that are printed using the concept of additive manufacturing. To meet desirable shape changes, stiffness can either be tailored or actively controlled to guarantee flexibility in the chord-wise (or span-wise) direction with tailored actuation forces. Hence, corrugated structures, segmented structures, reinforced elastomers or flexible matrix composite tubes embedded in a low modulus membrane are all possible structures for morphing skins.
\end{abstract} skin.

Keywords-Complaint rib mechanism, elastomers, flexible

\section{INTRODUCTION}

It was not until the late 19th Century that the concept of flight took the entire world by awe and surprise, and now it has become one of the most significant commodities that describes economies of several nations. From a recent study, conducted by the International Air Transport Association (IATA), global aviation contributes to $\$ 2.7$ Trillion (3.6\%) of the world's Gross Domestic Product (GDP). Having this big of an impact on the global economy, it is only natural for airlines to set their ultimate goal to profit and/or save their finances out of this. But this procedure of saving finances/economy cannot compromise enhancement in their services. This gap between the Service sector and the economy is only bridged by the quality and performance of the aircrafts that the airlines purchase.

The expected result out of every aircraft that any airline purchases is to transport a large amount of payload, be it passengers and/or cargo, at the least possible expense incurred to the airline itself. A major portion of the expense is occupied by Fuel, followed by airport parking/terminal charges and maintenance/service of aircrafts. This only calls for aircrafts to be manufactured in such a way that it is highly efficient in case of fuel consumption. Thanks to the relentless advancements of technology since the early 20thth century, we, the people of the 21 st century, reap the profits of highly fuel efficient aircrafts. Several manufacturers of airframes and propulsion systems, from all around the world have invested their profits into research and development organizations to improve the technology in order to enhance the fuel economy of their respective systems.

Morphing technology on aircraft has grabbed interest over the last decade because it improves the performance and efficiency over a wider range of flight conditions. Morphing wings can also be defined as wings that changes its configuration to maximize its performance at various different flight conditions and purpose. Morphing aircraft wings have requirements such as flexible skins that can undergo large strains and have low in-plane stiffness. For example, a radical change in configuration, i.e. wing geometry in flight may improve overall flight performance during take-off, cruise and landing.

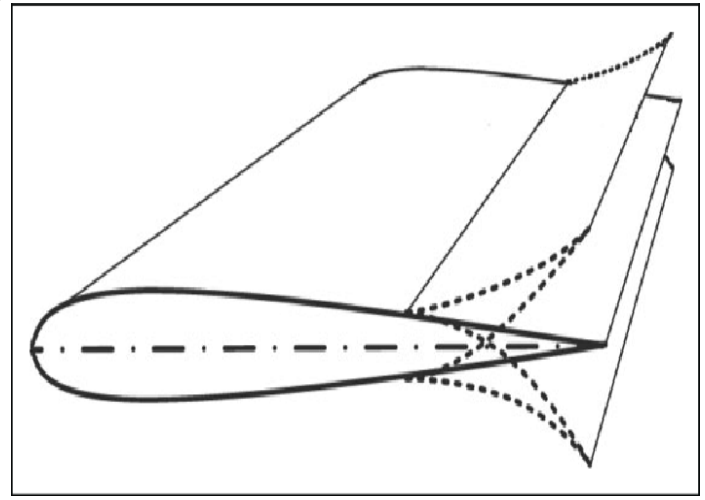

Fig. 1. Basic Idea of a Chord-Wise Morphed Wing

\section{METHODOLOGY}

A. Airfoil Selection

Selig1223 from the Selig series, FX74MODSM from the WORTMAN series and Eppler 423 from the Eppler series of airfoils were shortlisted. Originating from the Low Speed and Low Reynolds number regime, these airfoils were analyzed and selected by means of reference scoring method.

The parameters considered were $\mathrm{Cl}_{\max }, \mathrm{Cd}_{\min }$, Stall angle, $\mathrm{C}_{1} / \mathrm{C}_{\mathrm{d}}$ and ease of fabrication. The airfoil with the most favourable outcome of the listed parameters would be scored a maximum of 3 and the airfoil with the least favourable outcome would be scored a minimum of 1 . 


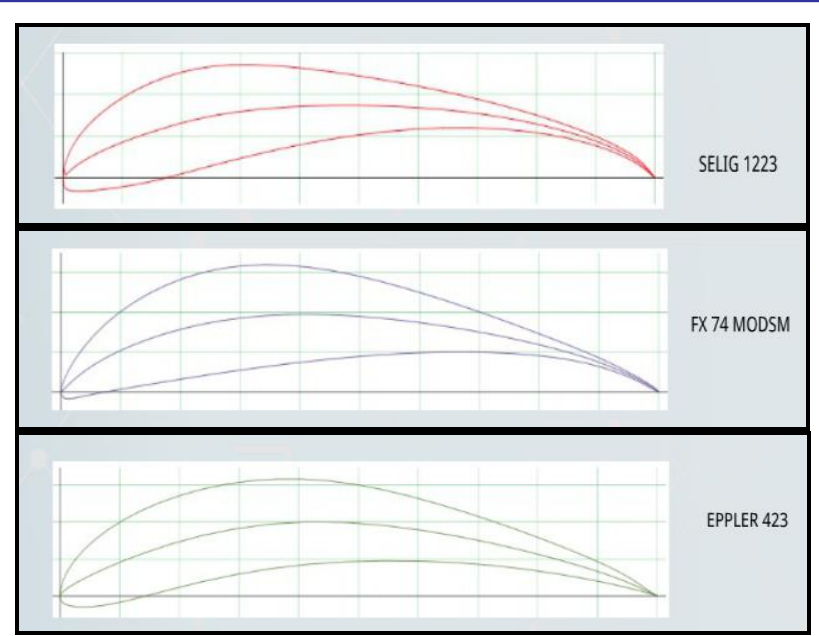

Fig. 2. Airfoil Profiles

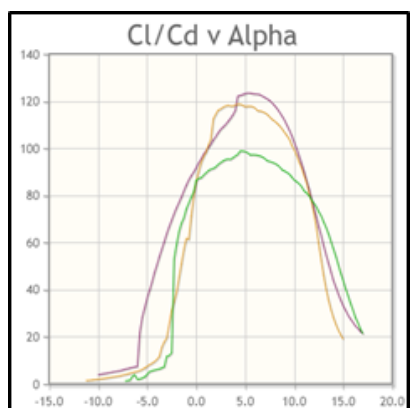

Fig. 3. Graph of $\mathrm{C}_{\mathrm{l}} / \mathrm{C}_{\mathrm{d}}$ vs. AOA

The airfoil characteristic plots such as $\mathrm{C}_{1}$ vs. AOA, $\mathrm{C}_{1}$ vs. $\mathrm{C}_{\mathrm{d}}, \mathrm{C}_{\mathrm{m}}$ vs. $\mathrm{AOA}$ and $\left(\mathrm{C}_{\mathrm{l}} / \mathrm{C}_{\mathrm{d}}\right)$ vs. $\mathrm{AOA}$ at $\mathrm{Re}=500,000$ were studied and the reference scoring method was employed to choose the best out of all three airfoils. The plot above shows the Lift coefficient trend with respect to angle of attack. We further observe that $\mathrm{S} 1223$ has the best stall performance followed by E423. But we also observe that FX74modsm has the highest lift coefficient.

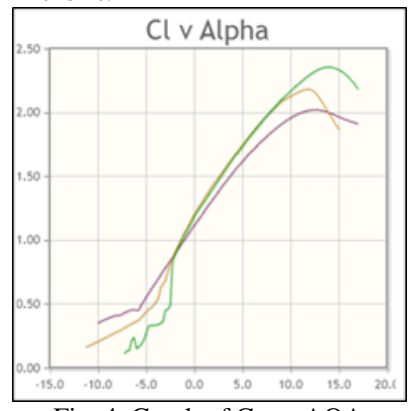

Fig. 4. Graph of $\mathrm{C}_{1}$ vs. AOA

The plot above shows us the variation of lift coefficient with respect to drag coefficient. We further observe that E423 has the least drag coefficient followed by FX74modsm. We also observe that the S1223 has the highest drag coefficient value out of all the three airfoils. Hence we give E423 the highest score of 3 followed by 2 for FX74modsm and the least favourable score of 1 to $\mathrm{S} 1223$.

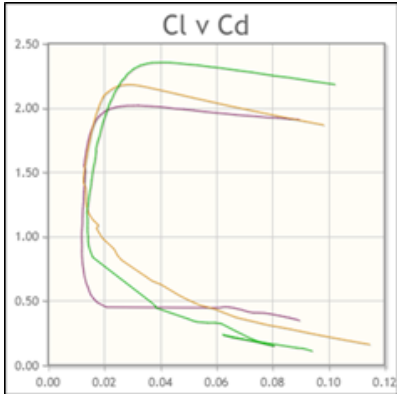

Fig. 5. Graph of $C_{1}$ vs. $C_{d}$

The figure 3 shows the variation of aerodynamic efficiency, that is the ratio of $C_{1}$ to $C_{d}$ versus angle of attack. We observe that the E423 has the highest $C_{1}$ to $C_{d}$ ratio at approximately $5^{\circ}$ followed by FX74modsm and then the S1223 has the least $C_{l}$ to $C_{d}$ ratio relative to the other two. Hence, E423 gets the highest score of 3 and S1223 gets the least score of 1 .

The table below is the integral representation of the reference scoring methodology employed to choose one Airfoil. The scores for individual parameters are distributed and then the Airfoil's total score is computed.

\begin{tabular}{|cccc|}
\hline \multicolumn{4}{c}{ Table 1. Reference Scoring Chart } \\
\hline Airfoil & $\mathrm{S} 1223$ & FX74MODSM & E423 \\
Parameter & 3 & 2 & 1 \\
$\mathrm{Cl}_{\max }$ & 1 & 2 & 3 \\
$\mathrm{Cd}$ min & 3 & 1 & 2 \\
$\alpha_{\text {stal }}$ & 1 & 2 & 3 \\
$\mathrm{Cl} / \mathrm{Cd}$ & 1 & 2 & 3 \\
Ease of Fabrication & & & 12 \\
\hline Total Score & 9 & 9 & 12 \\
\hline
\end{tabular}

\section{B. Airfoil Selection}

The primary task, to be able to define any analysis was to figure out a method to modify the E423 airfoil. It is a highly tedious task to be changing the co-ordinates of the airfoil empirically to replicate a morphed trailing edge. To avoid this, we imported the airfoil co-ordinates into CATIA Generative Shape Design.

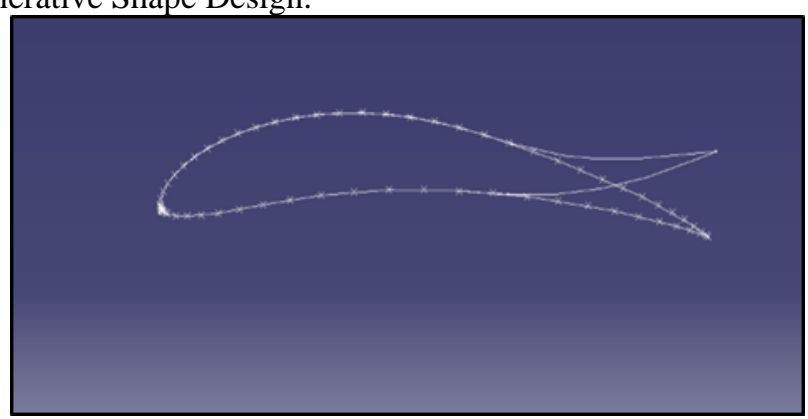

Fig. 6. Imported Airfoil Co-Ordinates

The airfoil profile was extruded to form a surface. This airfoil surface was deformed to imitate a control surface deflection by using the SHAPE MORPHING tool. And once the surface was morphed, a 2-D profile of the morphed airfoil was projected. This morphed airfoil profile was used to create a 2-D surface which was then imported into the ANSYS Workbench. 


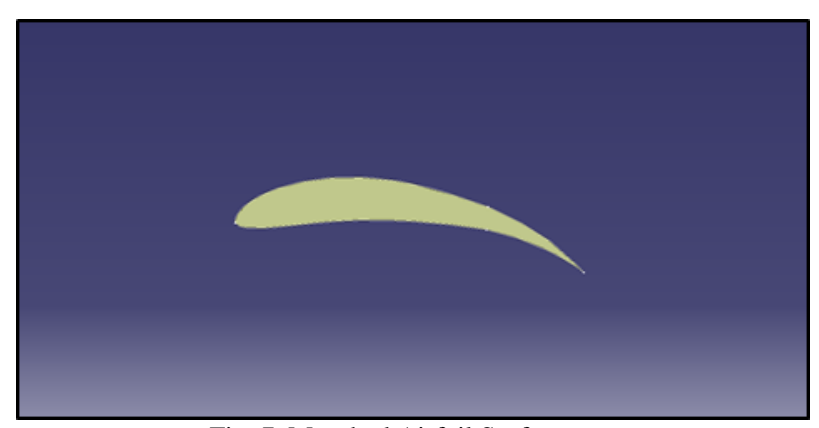

Fig. 7. Morphed Airfoil Surface

The airfoil surface was saved in .igs format and was then imported into ANSYS Fluent. The Geometry of a test section was sketched and the airfoil surface was removed to create the impression of the airfoil cavity using Boolean tool.

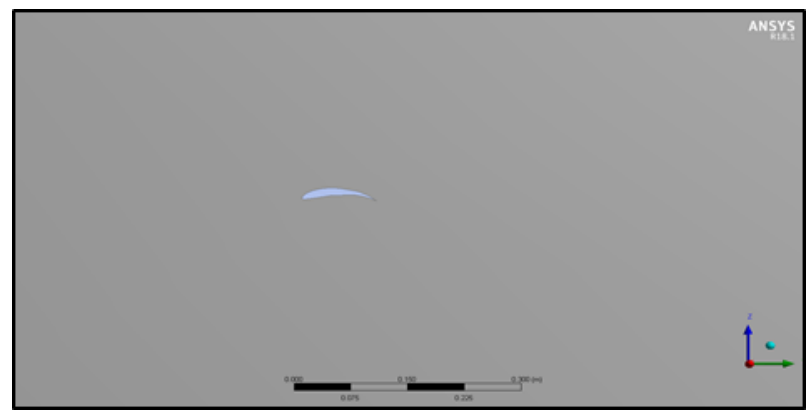

Fig. 8. ANSYS Geometry

A fine Mesh with a sufficient inflation layers was created in the test section with 28715 nodes and 48591 elements.

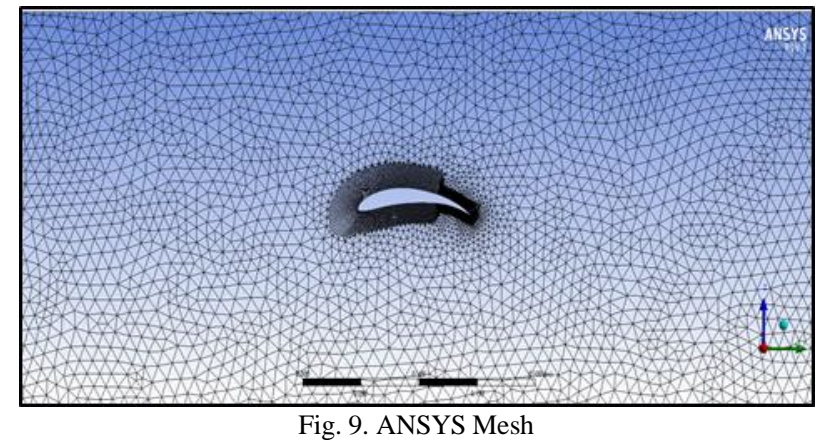

Named sections of the Inlet, Outlet, Wall and Airfoil walls were created in order to help set up the analysis. The model was set up to compute in steady state, pressure based results of the airfoil with a constant flow of air at $20 \mathrm{~m} / \mathrm{s}$ inlet velocity. The model was Hybrid Initialized and was run for calculations. The set-up also involved reporting the drag and lift coefficient plots at the solution.

The morphed airfoil was analyzed and the pressure and velocity contours were obtained along with the lift and drag coefficients. The above steps were repeated with a hinged airfoil and the corresponding results were obtained.

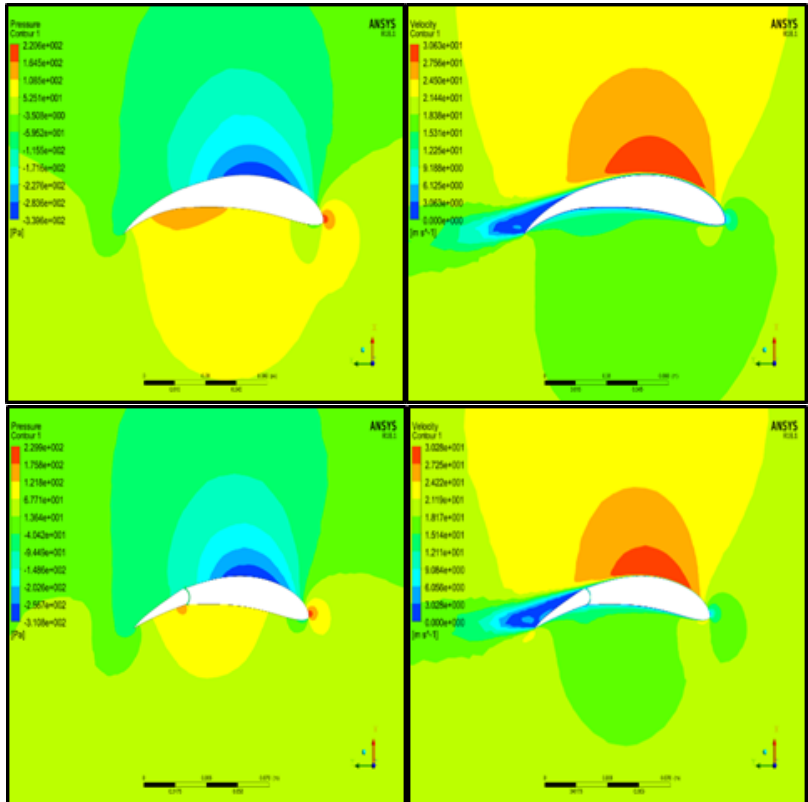

Fig. 10. (a) Pressure Contour of Morphed (Top Left), (b) Velocity Contour of Morphed (Top Right), (c) Pressure Contour of Hinged (Bottom Left), (d)

Velocity Contour of Hinged (Bottom Right)

The table below shows us the lift and drag coefficients along with the aerodynamic efficiency of morphed and hinged airfoil profiles.

\begin{tabular}{|c|c|c|}
\hline Parameters & Hinged & Morphed \\
\hline $\mathrm{C}_{1}$ & 0.4481 & 0.5527 \\
\hline $\mathrm{C}_{\mathrm{d}}$ & 0.026 & 0.0273 \\
\hline $\mathrm{C}_{\mathrm{l}} / \mathrm{C}_{\mathrm{d}}$ & 17.2346 & 20.2454 \\
\hline
\end{tabular}

\section{PRELIMINARY DESIGN}

\section{A. Designing the Prototype}

The goal was to keep the monolithic structure as the rib design and a strong leading edge region. The resulting design was generated as shown below.

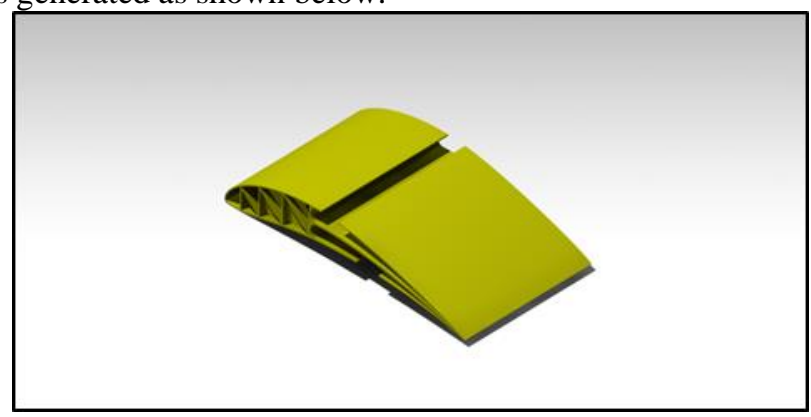

Fig. 11. Inner Compliant Core

The figure above shows the structure to possess the leading edge truss and a compliant structure along the mean camber line after $45 \%$ of the chord all the way up until the trailing edge. Corrugations were preserved and were moved further upstream.

The two part wing structure was put through a Structural Analysis Test for Maximum Elastic Von-Mises Strain. The Steps followed are as mentioned below. 
- The product was converted to ".iges" format and imported into Ansys Work bench static Structural Geometry Window.

- The mechanical properties of the materials used was saved at the Engineering Data tab as follows.

Table 3. Mechanical Properties of PLA and TPU input at Engineering Data

\begin{tabular}{|l|l|l|l|}
\hline Material & $\begin{array}{l}\text { Density } \\
(\mathrm{kg} / \mathrm{m} 3)\end{array}$ & $\begin{array}{l}\text { Young's } \\
\text { Modulus } \\
(\mathrm{MPa})\end{array}$ & $\begin{array}{l}\text { Poisson's } \\
\text { Ratio }\end{array}$ \\
\hline PLA & 1260 & 2454 & 0.33 \\
\hline TPU & 1350 & 12 & 0.38 \\
\hline
\end{tabular}

- The saved material data was assigned to their respective parts.

- The model was meshed and refined to the second order. This was done to increase the number of nodes thereby facilitating an accurate result.

The Inner Core Element, 3D printed out of PLA, was to be covered using a flexible skin which also shares the same profile as that of the chosen airfoil. This Skin was 3D printed using TPU filament and was done to keep a smooth surface exposed to the air (fluid). The following figure represents what the skin will look like.

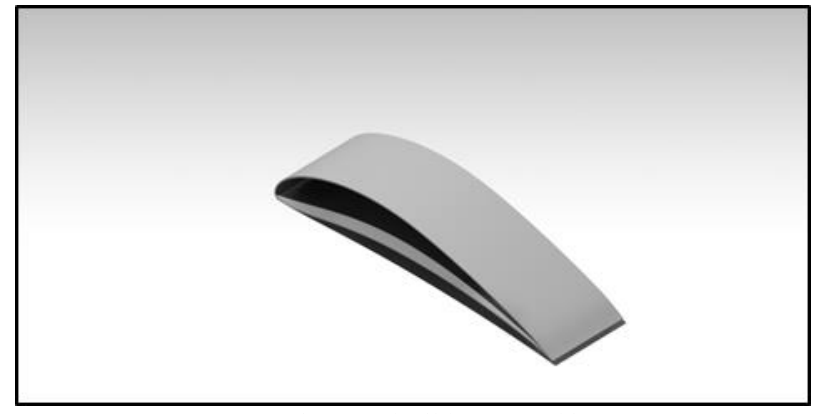

Fig. 12. Flexible Outer Skin

The figure below shows us how the Compliant Inner Core easily slides into the Flexible Outer Skin.

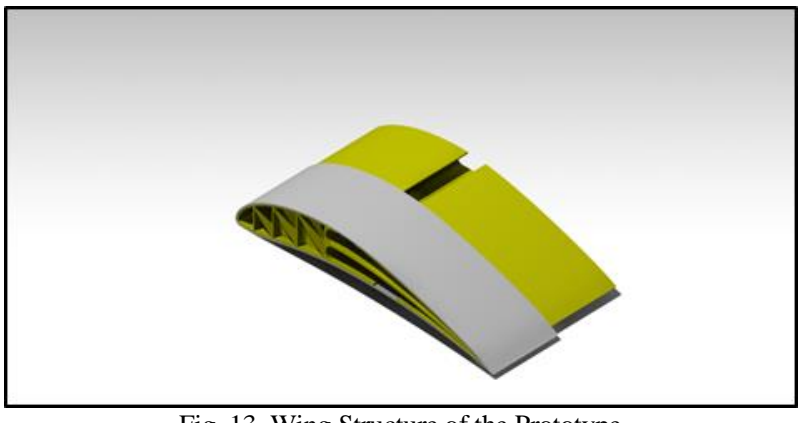

Fig. 13. Wing Structure of the Prototype

B. Structural Analysis

A structural analysis was conducted and the steps mentioned below were followed.

- Engineering Data was updated with mechanical properties of PLA filament and the Inner core was imported into geometry window.

- This was further meshed and the analysis settings were updated as follows.

- The entire truss leading edge region was identified as a fixed support and a force of $100 \mathrm{~N}$ was applied at the control horn in the pulling direction which makes the control surface deflect down.

- The figure below shows the location of the fixed support and the location where the load is applied and also the direction of the load.

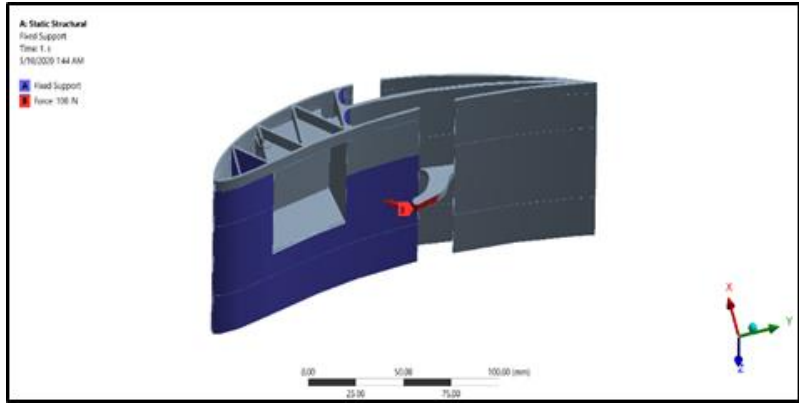

Fig. 14. Locations of Fixed Support and Load Application

- The model was analyzed for Equivalent Von Mises Strain and Total Deformation.

- The following figure shows us the maximum deformation to be recorded at $16.252 \mathrm{~mm}$ and the maximum strain at the control horn to be $0.03203 \mathrm{~mm} / \mathrm{mm}$ and at the maximum strain at the upper mean camber line to be $0.00711 \mathrm{~mm} / \mathrm{mm}$.

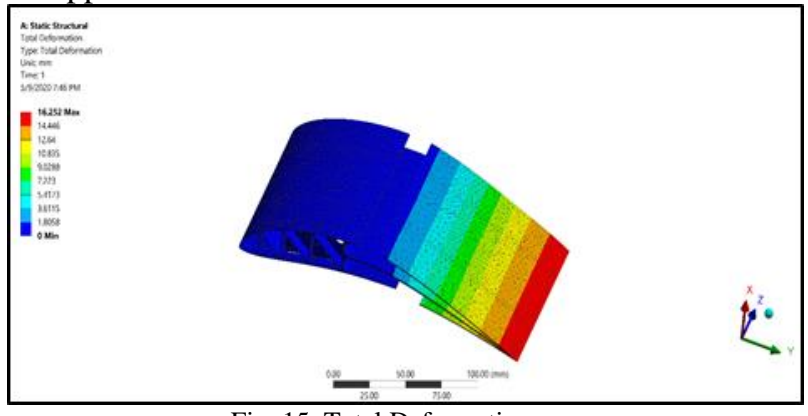

Fig. 15. Total Deformation

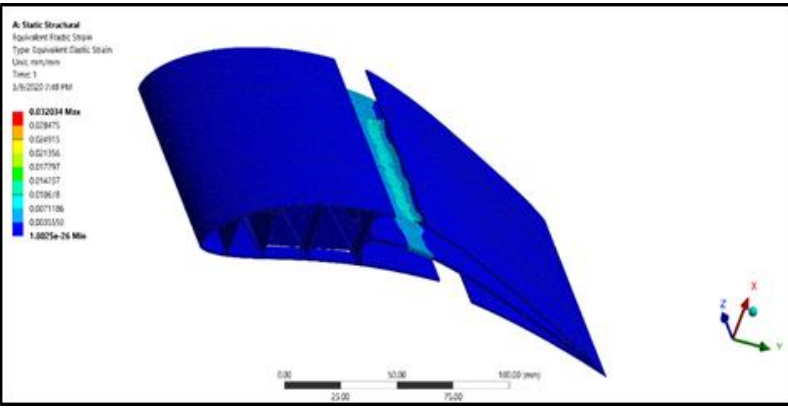

Fig. 16. Maximum Strain at Upper Mean Camber Line

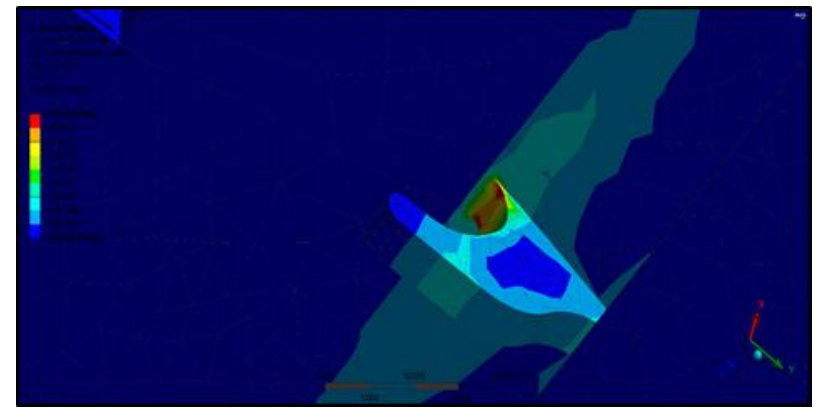

Fig. 17. Maximum Strain at Control Horn 


\section{MORPHED WING PROTOTYPE}

For our final prototype model we have used the 3-D printing method. 3-D printing is often referred to as the additive manufacturing of which we have used materials like PLA for the main structure of the wing and TPU for the skin. These two materials, when used together, are very flexible and tougher.

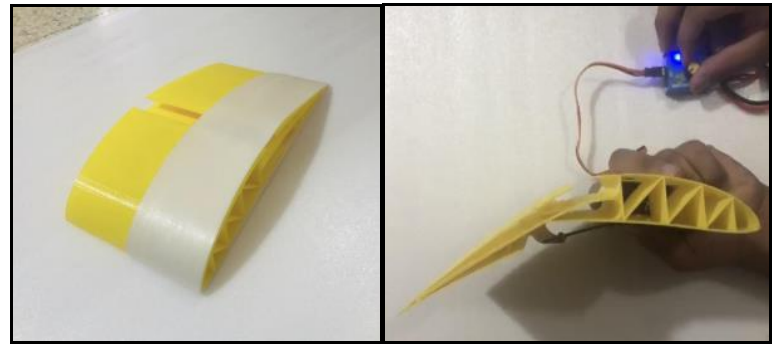

Fig. 18. Morphed Wing Prototype

\section{RESULTS AND DISCUSSIONS}

The mechanism was tested and proven for enhancing aerodynamic as well as structural efficiency. The design was fabricated and the structural analysis was experimentally verified.

The following results were observed during the experimental testing of the assembly after $3 \mathrm{D}$ printing the model.

\begin{tabular}{|l|l|l|}
\hline Parameters & Computational & Experimental \\
\hline $\begin{array}{l}\text { Max Down } \\
\text { Deflection }\end{array}$ & $16 \mathrm{~mm}$ & $20 \mathrm{~mm}$ \\
\hline Max Up Deflection & $14 \mathrm{~mm}$ & $18 \mathrm{~mm}$ \\
\hline
\end{tabular}

The model was extensively tested for fatigue by means of recording the operational time and the number of cycles of Neutral-UP-Down-Neutral Sequence. The following were the results of this experimental test to determine the Optimum number of operational cycles.

\begin{tabular}{|l|l|l|l|l|}
\hline $\begin{array}{l}\text { Cycle } \\
\text { Sequence }\end{array}$ & $\begin{array}{l}\text { Cycle } \\
\text { Duration }\end{array}$ & $\begin{array}{l}\text { Number of } \\
\text { Cycles }\end{array}$ & $\begin{array}{l}\text { Average } \\
\text { Down } \\
\text { Deflection }\end{array}$ & $\begin{array}{l}\text { Average Up } \\
\text { Deflection }\end{array}$ \\
\hline $\begin{array}{l}\text { N-Up- } \\
\text { Down-N }\end{array}$ & $300 \mathrm{~s}$ & 84 & $19 \mathrm{~mm}$ & $15 \mathrm{~mm}$ \\
\hline & $600 \mathrm{~s}$ & 200 & $23 \mathrm{~mm}$ & $19 \mathrm{~mm}$ \\
\hline
\end{tabular}

As and when the duration of run time of the Inner Core was increased, it was observed that there was a slight increase in the deflection values. This experimental test was conducted in a rather primitive arrangement and helped us empirically determine the maximum number of times it would be safe to operate this compliant mechanism. It was determined that any more number of cycles after the 300 mark would result in a partial structural failure, therefore considering a FOS of 0.5 , it was empirically established that
150 cycles within a time frame of 800 s was the optimum number of cycles.

\section{ACKNOWLEDGMENT}

We thank the writers whose research papers we referred and developed the baseline for our research work, which we were able to change and deliver good results according to our requirements. Our mentor, Dr. R Rajendran, we are grateful to him for his helpful feedback. We extend our gratitude to Flexfoil (by FlexSys Inc.) for the inspiration. The variable surface controls of FlexFoil, geometrically reflect a major change over traditional aircraft flaps. The FlexFoil control surface adjusts wing cambers as they are moving rather than utilizing the heavy and bulky system of the regular wing assemblies, by leveraging the inherent elasticity of aviation grade materials

\section{REFERENCES}

[1] MichaelS. Selig, James J. Guglielmo, Andy P. Broeren and Philippe Giguere, "Summary of low-speed airfoil data". Volume 1, Issue June, 1995

[2] Daochun Lia, Shiwei Zhaoa, Andrea Da Ronch, "A review of modelling and analysis of morphing wings". Progress in aerospace sciences. Volume 100, Issue June, 2018.

[3] Adrzej Tarnowski, Jacek Meiloszy, Tomasz Goetzendorf-Grabowski, "Morphing wing with surface discontinuity- Comparative tests". 31st Congress of the International council of the Aeronautical sciences, Issue 9th September, 2018

[4] Karla Telidetzki, "Application of Jetstream to a suite of aerodynamic shape optimization problems". Issue 2014

[5] Dean Ninian and Sam M Dakka, "Design, development and testing of shape shifting wing model". Issue 1st November 2017.

[6] Mark Gilbert, "Kirigami inspired honeycomb wing box and flexible matrix composite skin for micro air vehicles". Issue October 2010.

[7] Michael D Skillen and William A Crossley, "Modelling and optimization for morphing wing concept generation". National Aeronautics and Space Administration STI Program. Issue March 1st, 2007.

[8] Jian Sun, Leng Jinsong, Qinghua Guan, "Morphing aircraft based on smart materials and structures: A state-of-art review". Article in Journal of Intelligent Material and Structures. Issue February 2016.

[9] Steven T Patton, Chenggang Chen, Jianjun Hu, Lawrence Grazulis, Amanda M Schrand and Ajit K Roy, "Characterization of thermoplastic polyurethane(TPU) and Ag-carbon black TPU nanocomposite for potential application in additive manufacturing". Issue 29 December 2016

[10] Yubo Tao, Peng Li, Sheldon Q Shi, "Application of a thermoplastic polyurethane/polylactic acid composite filament for 3D-printed personalized orthosis". Article in Materiali in Tehnologije. Issue February 2019.

[11] Francesco Previtali, Andres F. Arrieta, and Paolo Ermanni, "Performance of a Three-Dimensional Morphing Wing and Comparison with a Conventional Wing”. AIAA Journal. Issue 25 December 2014.

[12] David A Burdette, Joaquim R R A Martins, "Design of a transonic wing with an adaptive morphing trailing edge via aerostructural optimization". Issue 2018. Elsevier Masson SAS.

[13] Giulio Molinari, Andres F. Arrieta, Michel Guillaume, Paolo Ermanni, "Aerostructural Performance of Distributed Compliance Morphing Wings: Wind Tunnel and Flight Testing”. AIAA Journal. Issue 25 October 2014

[14] Sridhar Kota, Russell Osborn, Gregory Ervin, Dragan Maric, "Mission Adaptive Compliant Wing - Design, Fabrication and Flight Test”. RTO-MP-AVT-168. Issue 2006. 